Research Support

November 1998

University of Michigan Business School

CHEAP TALK ON THE WEB: THE DETERMINANTS OF

POSTINGS ON STOCK MESSAGE BOARDS

WORKING PAPER \#98025

BY

PETER WYSOCKI

UNIVERSITY OF MICHIGAN BUSINESS SCHOOL 


\title{
Cheap Talk on the Web: The Determinants of Postings on Stock Message Boards
}

\author{
by \\ Peter D. Wysocki ${ }^{*}$ \\ University of Michigan Business School \\ 701 Tappan Street \\ Ann Arbor, MI 48109-1234 \\ Telephone: (734) 763-6820 \\ Fax: (734) 936-0282 \\ Email: wysockip@umich.edu
}

November 1998

\begin{abstract}
This paper examines the cross-sectional and time-series determinants of message-posting volume on stock message boards on the Web. I test whether variation in message-posting volume is just noise or is related to underlying firm characteristics and stock market activity. Using a sample of over 3,000 stocks listed on Yahoo! message boards, I find that cumulative posting volume is, on average, highest for firms with extreme past returns and accounting performance, high market capitalization, high price-earnings and market-to-book ratios, high volatility and trading volume, high analyst following and low institutional holdings. Changes in daily posting volume are associated with earnings-announcement events and daily changes in stock trading volume and returns. Overnight message-posting volume is found to predict changes in next day stock trading volume and returns. Rational and behavioral explanations for the observed pattern in messageposting activity are discussed.
\end{abstract}

\footnotetext{
* I am grateful for the comments of Mark Bagnoli and workshop participants at the University of Michigan. I would
} also like to thank Janine Joseph and Dan Weimer for their able research assistance. The usual disclaimer applies. 


\author{
Quick Summary of Results \\ "Cheap Talk on the Web: The Determinants of Postings on Stock Message Boards" \\ Peter D. Wysocki (wysockip@umich.edu) \\ University of Michigan Business School Working Paper, November 1998
}

What affects total message posting volume for stocks listed on Yahoo! message boards?

On average; the total number of messages posted is:

- $13 \%$ lower for NYSE firms;

- $11 \%$ \& $47 \%$ higher for firms in the highest and lowest ROE quartiles, respectively;

- $28 \%$ higher for firms in the highest change in ROE quartile;

- $22 \%$ and $28 \%$ higher for firms in the highest and lowest stock return quartiles, respectively;

- $10 \%$ higher for every 10 unit change in the price-earnings ratio (i.e. $\mathrm{PE}=10$ to 20 );

- $10 \%$ higher for every 1 unit change in the market-to-book ratio;

- $66 \%$ lower for dividend-paying firms;

- $10 \%$ higher for every doubling in the number of individual shareholders;

- $34 \%$ higher for every doubling in the market cap of the firm;

- $23 \%$ higher for every doubling of monthly trading volume;

- $2 \%$ higher for each additional analyst following the firm;

- $3 \%$ higher for each $1 \%$ increase in the standard deviation of monthly stock returns;

- highest in the technology and healthcare sectors and lowest for financial and utility sectors.

What affects daily changes in message posting volume?

On average, message-posting volume is:

- $17 \%, 27 \%$ and $78 \%$ higher than normal the day before, the day of, and the day after an earnings announcement;

- $3.1 \%$ higher for every $10 \%$ increase in daily stock trading volume;

- $2.7 \%$ higher for every $1 \%$ drop in the today's stock price;

- $1.8 \%$ higher for every $1 \%$ change in yesterday's stock price;

Can past message-posting volume predict next-day stock market activity?

- A ten fold increase in overnight message postings (i.e. 10 to 100 messages) leads to a $15.6 \%$ average increase in next day stock trading volume;

- A ten-fold increase in overnight message postings (i.e. 10 to 100 messages) leads to $0.7 \%$ average abnormal next day stock return. 


\section{Introduction}

This paper examines the cross-sectional and time-series determinants of message-posting volume on Internet stock message boards. Stock message boards, also known as investor chat rooms, are sites on the World Wide Web and other on-line services where individuals discuss publicly-traded companies by posting messages that can be read by anyone visiting the board. Message board posting activity has grown from almost nothing two years ago to thousands of messages each day in recent months (see, for example, Harmon, 1998, and Bennett, 1998). However, little is known about these boards and their potential impact on capital markets.

What is certain is that stock message boards have attracted the interest of the media, companies, and securities regulators. There have been numerous claims in the popular press that message board "cybergossip" has the power to move stock prices'. A recent Wall Street Journal article reported that "as a largely unregulated and anonymous medium, the Internet is a magnet for unscrupulous stock promoters in search of a fast way to reach millions of potential investors" (WSJ, October 29, 1998). Many firms now diligently monitor the message boards and even participate in the discussions to "set the record straight" or engage in damage control (see, for example, Goldstein, 1998). In response to a range of complaints about potential Internet fraud, the SEC recently established a new Office of Internet Enforcement to monitor message board posting activity for possible securities law violations. Firms and regulators are devoting real resources to address the perceived problems of posting activity. However, these actions are taking place without good information on what is driving the message board posting phenomenon.

This paper provides the first systematic evidence on which factors, if any, determine stock message board posting volume for over 3,000 stocks listed on Yahoo! message boards. I test whether variation in message-posting volume is just noise or is related to underlying firm characteristics and stock market activity. I also attempt to determine if message-posting activity reflects (a) rational gathering, processing and reaction to information by investors, or (b)

\footnotetext{
${ }^{1}$ Recent news articles which discuss possible links between message postings and subsequent stock price moves include Batsell (1998), Goldstein (1998), Maremount (1998), and Medill (1998).
} 
irrational/ behavioral actions on the part investors. I find that message-posting volume between December 1997 and June 1998 is, on average, higher for firms with extreme past stock returns and accounting performance, high market capitalization, high price-earnings and market-to-book ratios, high past volatility and trading volume, high analyst following, and low institutional holdings. Firms in the technology, service, and healthcare sectors also tended to have higher posting volume.

I also examine changes in daily message-posting volume for 50 of the most active stocks listed on Yahoo! message boards between January and August 1998. The time-series results show that daily posting volume increases during earnings announcement periods and is associated with contemporaneous changes in daily trading volume and stock returns and with prior day stock returns. The most interesting finding is that message-posting volume appears to predict future trading volume and future stock returns. I find that, after controlling for previous day stock returns and trading volume, changes in overnight posting volume predicts next day trading volume and abnormal stock returns. The feasibility of the trading strategy is discussed in the paper.

At a purely descriptive level, my empirical results show that message-posting volume is related to underlying firm characteristics and market activity. The empirical findings demonstrate that posting activity is not just noise, but is associated with stock market information flows. For example, earnings announcement events and short-run and long-run changes in returns and trading volume are associated with increased posting volume. These findings suggest that posting activity is related to the arrival of information in the market and the interpretation of this information by market participants (see, for example, Kim and Verrecchia, 1991; Harris and Raviv, 1993; Kandel and Pearson, 1995).

The empirical results can be interpreted as being consistent with rational investor/poster behavior. For example, posting volume is highest for firms in the high technology sector and firms with high price-earnings and market-to-book ratios, and extreme past performance. A plausible interpretation of these findings is that posters focus on firms with the largest information asymmetry, the poorest accounting information, the highest uncertainty and risk, and 
the greatest likelihood of generating future information flows. Many of these same characteristics also determine analyst following (see, for example, Bhushan, 1989). Not surprisingly, I also find that analyst following is positively associated with posting activity. Therefore, message-posting activity can be viewed as a rational phenomenon where investors use message boards to gather, process, and react to information.

On the other hand, variation in message-posting activity could have a behavioral explanation. For example, investors and posters could react to pseudosignals, irrationally fixate on "glamour stocks", or place too much weight on past information (see, for example, DeBondt and Thaler, 1985, DeLong, Shleifer, Summers, and Waldman, 1990; Lakonishok, Shleifer and Vishny, 1994). The high posting volume for high technology firms, high price-earnings and high market-to-book firms, and firms with extreme past performance could be interpreted as irrational fixation on "glamour stocks" or dated information.

Regardless of the interpretation of the phenomenon, message-posting activity is clearly related to firm characteristics and market activity. Measures of message board postings could become a new barometer of information flows in equity markets or provide insights into investor psychology. Stock message boards contain a wealth of new data on investor activity and should prove to be a promising new area for finance research.

The remainder of the paper is organized as follows. Section 2 provides background information on stock message boards and outlines the research approach undertaken in the paper. Section 3 describes the data sample. Section 4 details the empirical tests. The concluding section summarizes the results and discusses the research implications.

\section{Background}

Early incarnations of stock message boards, also known as chat rooms, appeared nearly two decades ago soon after the introduction of on-line services. They were originally founded to electronically disseminate information to individual investors and overcome some of the information advantages of Wall Street insiders. In the early years, these sites were investment 
backwaters with little activity. However, the recent growth of the World Wide Web and on-line stock trading has greatly increased the popularity of these virtual investor forums. Figure 1 shows that level of daily posting activity has grown dramatically during 1998 for the 100 most active firms listed on Yahoo! stock message boards ${ }^{2}$. There is a clear upward trend in daily posting activity. In addition, there is wide variation in the level of daily posting volume for these stocks. Posting activity significantly drops on weekends compared to trading days. This weekday vs. weekend effect could reflect differences in information arrival during trading and non-trading hours (see, for example, French and Roll, 1986).

\section{[ Insert Figures 1 here]}

There has also been a recent proliferation in the number of sites sponsoring message boards. Some of the most active sites include Yahoo!, The Motley Fool, Silicon Investor, StockTalk, and The Raging Bull ${ }^{3}$. The message boards for certain stocks have become active gathering places to share timely company information, engage in debate about company financials, provide predictions about future stock performance, stoke the corporate rumor-mill, spread misinformation, or simply rant about nothing. Anecdotal evidence indicates that messageposting activity varies considerably across stocks, with some small unprofitable start-ups attracting more interest than long-established companies.

Users can typically access a stock message board at a Web site by typing in ·a stock's ticker symbol. "Posters", individuals who post messages, must register with the board operator and choose an alias before posting messages. Posters have the option to post new messages or respond to current topics. "Lurkers", individuals who just want to read message postings, usually do not have to register. The anonymous nature of these boards makes it difficult to tell who is posting messages, but it appears that small investors, analysts, public relations officers, interested bystanders, teenage computer hackers, and scam artists are among the active participants.

\footnotetext{
${ }^{2}$ The 100 stocks were selected from all 8,011 stocks on Yahoo! message boards based on the highest cumulative message posting volume on July 1, 1998.

${ }^{3}$ The addresses of these sites are http://messages.yahoo.com/yahoo/Business_and_Finance/Stocks/index.html, http://www.fool.com, http://www.siliconinvestor.com, http://www.stock-talk.com, and http://www.ragingbull.com.
} 
Casual observation shows that message-posting volume varies considerably across stocks and over time. For example, on August 18, 1998 over 1,740 messages were posted on the Yahoo! message board dedicated to Dell Computer. On the other hand, only 2 messages were posted on the same day on the Yahoo! message board dedicated to USX - U.S. Steel Group. Figure 2 shows that message posting volume also varies dramatically within a day. Message posting activity is highest during security-market trading hours. This evidence raises fundamental questions about when, why and which stocks attract postings? Is posting activity related to fundamental firm characteristics, information in securities markets, investor sentiment, or is it just pure noise?

\section{[ Insert Figure 2 here]}

A quick inspection of message content would lead one to conclude that many postings are pure noise. Postings and subsequent replies often degenerate into "trash talk" and personal attacks with only limited connection to the stock. On the other hand, postings can evolve into sophisticated debates about company financial disclosures. For example, minutes after a company releases its earnings, posters often quickly begin to dissect, interpret, and debate the financial report on-line. The abundance of apparent disagreement on message boards could be a barometer of differences in investor opinion about market information. Harris and Raviv (1993) and Kandel and Pearson (1995) present models where trade in financial markets arises from differential interpretation of information by traders. Therefore, posting activity on stock message boards could provide a new and useful measure of difference in opinion about the meaning of new information releases. Message postings can also contain pieces of important and valuerelevant information not available from other public sources. For example, Bagnoli, Beneish and Watts (1998) obtain data on "whisper" forecasts of company earnings per share from stock message boards on the Web. They find that these unofficial forecasts of earnings are, on average, more accurate and are better proxies for market expectations of earnings than First Call analyst forecasts. Unfortunately, Bagnoli et al had to spent months reading and deciphering thousands of messages to create an arguably subjective data set. 
I take a different approach in this paper to evaluate message postings. My focus is on the volume, rather than the content, of messages posted on stock message boards. The goal of this paper is to determine whether message posting "traffic" is related to underlying firm characteristics and stock market activity. Message volume is both a summary measure of posting traffic and an objective construct that can be easily reproduced by other researchers and practitioners. Intuitively, the volume of posting activity should be a meaningful measure of information flows on stock message boards. Although I lose the information contained in the messages, my approach avoids the problems of subjectively screening and interpreting individual messages.

The goal of this study is to determine whether variation in message-posting volume is just noise or is associated with underlying firm characteristics and stock market activity. I also attempt to provide insights into whether message-board traffic reflects rational investor activity or a behavioral phenomenon. I examine these competing explanations by measuring the variation in posting volume across a range of firms with different characteristics and across time for individual firms.

\subsection{Research Approach - Cross Section}

The cross-sectional tests are designed to measure the association between fundamental firm attributes and long run message-posting volume. I propose the following set of firm characteristics as potential determinants of message-posting activity:

\section{Price-earnings ratio}

The price-earnings (PE) ratio is predicted to have a positive association with posting volume based on either rational or irrational interpretations of investor behavior. In a rational world, the PE ratio can be viewed as a proxy for future growth opportunities, or as a measure of the mismatch between current accounting income and future expected cash flows (poor accounting quality). Firms with high future growth opportunities or untimely financial accounting information are likely to have high relative information asymmetries between insiders, informed investors, and uninformed investors. Therefore, investors have the greatest 
incentive to search for information on high PE firms which is not available from other public sources. High PE firms should also have a higher likelihood of future information events as future growth options are exercised. Therefore, the characteristics of high-PE firms lead rational investors to engage in message-posting activity as they search for, process and react to information.

On the other hand, investors could fixate on certain types of "glamour" firms. Overexuberant investors would then irrationally bid up the stock price relative to current accounting income. This over-enthusiasm would result in high relative $\mathrm{PE}$ ratios and high posting activity as investors irrationally fixate on certain stocks. As the price bubble grows for the glamour stocks, there will be large difference in opinion about the "true" value of the stocks. These differences in opinion about firm value would also stimulate posting activity for high PE firms.

\section{Market-to-Book Ratio}

The market-to-book (MB) ratio is also predicted to have a positive association with posting activity. Similar to the price-earnings ratio, the market-to-book ratio can used to measure future growth opportunities, proxy for the quality of accounting information, and measure a firm's market valuation relative to fundamentals. Again, a positive association between the market-to-book ratio and message-posting volume could have rational and behavioral explanations.

\section{Dividend Payout}

Dividend-paying firms are predicted to have low posting volume. Dividend-paying firms tend to have assets-in-place, low growth opportunities, low information asymmetry, low likelihood of future information production, and low risk. Therefore, there are low benefits for rational investors to engage in information search for these firms on stock message boards. This leads to the prediction of low message posting volume for dividend-paying firms. 
\# of Shareholders

Posting volume is predicted to be positively associated with the number of individual shareholders in a firm. There is anecdotal evidence that message posters tend to be individual investors. Therefore, the larger the number of shareholders, the greater the likelihood that there will be an individual who will decide to post a message. Moreover, the larger the number of different shareholders, the greater the likelihood of differences in opinion about market information. These differences in opinion would generate posting activity as investors attempt to verify their priors about an information event.

\section{Institutional Holdings}

The level of institutional stock holdings should be negatively associated with messageboard posting volume. Large institutional investors often have direct access to company management and to research from Wall Street investment houses. Therefore, institutions have few incentives to look for or disseminate private information on message boards. In addition, firms with large institutional holdings are likely to be established firms with comprehensive public disclosures. Therefore, rational investors have few incentives to look for alternate sources of information for these types of firms.

\section{Trading Volume}

Trading volume is predicted to be positively associated with message posting volume. Harris and Raviv (1993) and Kandel and Pearson (1995) predict that trading volume arises from differences in investor opinion about market information. If differences in opinion also drive message board debate, then posting activity and trading volume should be closely related to each other. In addition, both trading volume and message-posting activity will reflect investor reaction to actual information releases.

\section{Size (Market Capitalization)}

Large market-capitalization firms are predicted to have a positive association with message-posting volume. Large-cap firms will, on average, have a larger investor following and a higher likelihood of information releases. Therefore, other things equal, large firms should attract more posting activity. 
\# Analysts

Analyst following is predicted to have a positive association with message-posting activity. Demand for analyst services should be highest when there are net benefits to information-intermediation services of analysts. Bhushan (1989) finds that analyst following is increasing in measures of firm information asymmetry and decreasing in measures of the quality of publicly available financial accounting information. Firms with these similar characteristics would provide incentives for rational investors to search for alternate sources of information on stock message boards. Therefore, analyst following should be positively related to posting volume. Moreover, anecdotal evidence (see, example, Bagnoli et al (1998)) suggests that message-posting content often focuses on analyst forecasts of earnings. Therefore, the presence of analysts may actually stimulate posting activity.

\section{Accounting Performance (ROE)}

Firms with extreme high and low return-on-equity (ROE) are predicted to have high posting volume. Firms with extreme ROE are more likely to generate future news (i.e., restructuring, takeover, entry by competitors, etc.). Therefore, firms with extreme accounting performance are predicted to generate higher posting activity as rational investors react to future news. If investors have an asymmetric loss function, then extreme profits and extreme losses will generate different levels of posting activity.

\section{Accounting Performance (change in ROE)}

Similar to the ROE predictions, firms with extreme changes in ROE should generate more current and future information releases. Such firms will attract more postings as investors react to and process the information releases.

\section{Market Beta and Variance of Total Returns}

Firms with greater systematic and nonsystematic risk are predicted to generate more message-posting activity. The frequency, implications, and impact of future information releases for high-risk firms should be greater than the effects of information releases for stable, low-risk firms. These information releases are likely to generate high levels of posting activity as 
investors rationally react to and interpret the information. Differences in opinion about the significance of information releases for high-risk firms will also stimulate additional messageposting activity.

\section{Stock Return Over Past Year}

Extreme past stock return is predicted to be positively associated with message-posting volume. Stock return over the previous 12 months can be a viewed as a measure of cumulative news events for a firm. Firms experiencing very good and very bad news are likely to generate more posting volume as investors rationally react to and interpret this information. Extremeperforming firms will also likely have follow-up information releases in the future (i.e. future financial distress). Alternatively, extreme past stock returns may represent investor overreaction to information. Both a rational and behavioral interpretations of extreme past stock returns could explain high posting volume.

\subsection{Research Approach - Time Series}

The time-series tests are designed to examine whether daily changes in posting volume is correlated with daily changes in stock market activity. These tests will determine if information in security markets is quickly reflected in changes in message-posting activity. I examine three fundamental measures of changes in market activity, namely, changes in daily stock trading volume, absolute value of daily abnormal stock returns, and actual daily abnormal stock returns. Changes in a firm's daily trading volume and the absolute value of daily stock returns are considered to be measures of actual news and the reaction to the news by market participants. These measures are predicted to have a positive association with changes in message posting volume as investors react to and process information. A major information event for most firms is the release of quarterly earnings information. I predict that daily message-posting volume will be significantly higher around earnings-announcement events as investors anticipate, search for, process, and react to earnings information. 


\section{Data Sample and Description}

The empirical tests make use of data from the Yahoo! message boards. I chose to analyze the stock message boards from Yahoo! because it is one of the more active message board sites covering a large fraction of stocks traded on U.S. equity markets ${ }^{4}$. Moreover, the Yahoo! message board site has fixed message boards for each stock. This contrasts with other sites that do not have single message boards for individual stock discussions. For comparison, I also collected cumulative posting volume for each stock on the Motley Fool site. On July 1, 1998, there were fewer stocks listed on the Motley Fool site as compared to the Yahoo! site. Moreover, the stocks on the Motley Fool site typically had lower posting volume. However, the correlation between the cumulative posting volume for stocks covered at both sites was $0.68^{5}$. This suggests that there are systematic determinants of posting-activity that are not specific to a given messageboard site.

\subsection{Cross-sectional Sample}

A total of 8,011 stocks were listed in 12 industry categories on the Yahoo! message boards on July 1, 1998. The design of the Yahoo! message board site makes it difficult to quickly obtain quick summary information on posting volume for all 8,011 stocks. Therefore, a webcrawler program was used to download 8,011 separate web pages containing information on the company name, stock ticker symbol, and cumulative message posting volume for each stock on July 1,1998 . There is wide variation in posting activity for the 8,011 stocks. Figure 3 shows that distribution of message postings is highly skewed. The majority of firms have less than 100 postings, but almost 100 firms had in excess of 10,000 total postings between December 1, 1997 and July 1, 1998.

\section{[ Insert Figure 3 here]}

The ticker symbols and company names of the 8,011 stocks were matched with the firms covered on the 1997 Compustat database. The matching procedure produced 7,593 firms with

\footnotetext{
${ }^{4}$ Other message boards focus on restricted categories of stocks. For example, the Silicon Investor site tends to limit its coverage to high technology companies.
} 
correctly matching names and ticker symbols on the 1997 Compustat database. Information on stock price, earnings, shareholders equity, dividend payout, shares outstanding, and stock exchange listing was collected from the Compustat database. Close inspection of the data indicated extreme outliers of calculated price-earnings and market-to-book ratios. Therefore, firms with price-earnings and market-to-book ratios more than 4 standard deviations from their respective sample means were removed from the sample. The remaining firm observations were merged with data from the 1997 CRSP database and the July 1998 update of the Disclosure database. Information on monthly returns and trading volume was collected from the 1997 CRSP database. Information on the number of individual shareholders, the number of IBES analysts, and the fraction of share held by institutional investors was obtained from the Disclosure database. Firms without complete information from the Compustat, CRSP or Disclosure databases were excluded from the sample. The final sample consists of 3,478 observations. It should be noted that the commercial databases used in this study typically cover larger, older, and more-established firms. Therefore, the data requirements may bias the final sample toward firms with these characteristics.

The descriptive statistics for the sample of 3,478 firms are presented in Table 1. The mean number of postings for all firms in the sample is 272 . However, as indicated in Figure 3, there is wide variation in the level of postings across firms. Panel B summarizes the posting activity for the 12 industry categories represented in the data sample ${ }^{6}$. The financial, service, and technology categories contain the largest number of firms. Average posting volume also varies across industry category. Technology and healthcare firms have 670 and 403 average postings per firm, respectively. Utility, financial, and capital goods firms have, on average, fewer than 100 total postings per firm. About 33\% of the firms in the sample trade on the New York Stock Exchange. The average posting level for NYSE firms is significantly lower than for firms traded on other exchanges. Firms that pay dividends have, on average, 162 postings which is well below the sample average.

\footnotetext{
${ }^{3}$ On July 1, 1998, there were 2466 stocks that are covered on both Yahoo! and Motley Fool message boards.

${ }^{6}$ These industries are based on the categories used by Yahoo! to identify related stocks.
} 
The mean, median, and standard deviation of the cross-sectional variables are presented in Panel B of Table 1. During 1997, the average firm in the sample had a $-3 \%$ return on accounting equity, $24.3 \%$ nominal stock return, price-earnings ratio close to 13 , market-to-book ratio of 3.36 , market beta of 0.97 , around 3.5 analysts as reported by IBES, equity market capitalization of $\$ 1.97$ billion, monthly trading volume of 37 million shares, $35 \%$ of shares held by institutions and 11,904 indiviidual shareholders.

\subsection{Time-series Sample}

The time-series sample consists of 50 stocks with the highest cumulative message posting volume on the Yahoo! message boards on July 1, 1998. The time and date of every message posted between January 1, 1998 and August 26, 1998 was collected for the 50 stocks from the Yahoo! message boards. A web-crawler gathered the required posting information for over a million postings from over 25,000 web pages. For each stock, I calculated (a) the number of messages posted each trading day, (b) the number of messages posted during trading hours each trading day, and (c) the number of messages posted during non-trading hours preceding each trading day. The daily message posting data was combined with daily trading volume and closing prices obtained from the Dow Jones News Retrieval Service ${ }^{7}$. Abnormal stock returns were calculated as the daily close-to-close percentage change in stock price minus the daily close-to-close change in the level of the NYSE Composite Index. Data on the daily level of the NYSE Composite Index was obtained from the NYSE Web Site.

Information on the date of company earnings announcements between January 1, 1998 and August 26, 1998 was collected from the Dow Jones News Retrieval Service for the 50 stocks.

\footnotetext{
${ }^{7}$ Stocks with incomplete daily stock trading data for the sample period are dropped from the sample and replaced with the stock with the next highest cumulative posting volume on July 1, 1998. The final sample size is 50 firms.
} 


\section{Empirical Tests}

\subsection{Analysis of Cross-sectional Results}

The sample of 3,478 firms was analyzed to determine if firm characteristics and stock market activity during 1997 are associated with message posting volume. The natural logarithm of total messages posted is used as the dependent variable because (a) message posting volume is highly skewed, and (b) it allows for economically-meaningful and easy-to-interpret regression coefficients. The cross-sectional regression results are presented in Table 2. I will focus my discussion on the statistically-significant coefficients ${ }^{8}$.

Even after controlling for other financial characteristics, there appears to be wide variation in industry posting activity. Firms in the technology and healthcare industries have $84 \%$ and $58 \%$ more postings, respectively, than firms in the basic materials industry. It appears that new and emerging industries attract more posting volume. This could be attributed to a rational story based on the high level of information production in these sectors. Alternatively, these sectors may currently contain a large number of "glamour" stocks that attract overvaluation and speculation. This contrasts with utility and finance firms which have $44 \%$ and $54 \%$ fewer postings, respectively, than firms in the basic materials industry.

Firms traded on the New York Stock Exchange have 13.4\% fewer postings than firms traded on the American and NASDAQ exchanges. Firms in the lowest ROE quartile have $47.4 \%$ more postings than firms in the middle two ROE quartiles. Firms in the highest ROE quartile also have $11.1 \%$ more postings than firms in the middle two ROE quartiles. Both of these differences are statistically significant at the $1 \%$ level. In addition, the firms in the lowest ROE quartile have significantly more postings than firms in the highest ROE quartile. It appears that investors focus on the firms with the poorest accounting performance. Possible explanations for this trend are (a) posters focus on start-up firms that often incur losses during their growth phase, and (b) low ROE firms are underperforming firms that may be subject to possible takeover rumors, managerial turnover, and financial distress. 
On the other hand, firms with the highest change in ROE (highest change in ROE quartile) have $48.3 \%$ more postings than firms in the middle two change in ROE quartiles. Therefore, posters appear to focus on firms with the largest improvement in recent accounting performance. Again, this is consistent with growing firms and firms with significant positive news events. Differential interpretation of the change in ROE news would also cause increased posting volume.

Firms in the lowest and highest annual stock return quartiles have $28.1 \%$ and $22.3 \%$ more postings, respectively, than firms in the middle two annual stock return quartiles. It appears that investors focus on the firms with extreme stock returns in the past year. Firms with extreme past stock returns are likely to have had significant news or information releases. Firms with the lowest returns also have the higher future likelihood of financial distress, litigation, or other newsworthy events. Firms with extreme returns are also likely to have higher risk (idiosyncratic and systematic). However, the regression results show that market betas (a measure of systematic risk) are not significantly related to postings.

Firms with higher $\mathrm{PE}$ and $\mathrm{MB}$ multiples have higher average posting volume. For example, an increase in the PE multiple from 10 to 20 will result in a $1 \%$ increase in postings. An increase in $\mathrm{MB}$ from 1 to 2 would also increase expected postings by $1 \%$. Dividend paying firms also have $66.2 \%$ fewer postings than non-dividend paying firms. High PE and MB firms and non-dividend-paying firms are likely to be growth firms with low assets-in-place, high information asymmetry, and high probability of future news events. Therefore, the high posting volume could reflect rational posting activity as investors search for, process and react to information. High PE and $\mathrm{MB}$ ratios could measure poor quality accounting information and rational investors have the highest incentive to search for other information on message boards for these types of firms. On the other hand, high relative $\mathrm{PE}$ and $\mathrm{MB}$ ratios may represent "glamour" or overvalued firms. Investor fixation on this type of firm would also be reflected in posting volume. These overvalued firms also may attract short-sellers who may engage in speculative posting activity.

\footnotetext{
${ }^{8}$ All variables discussed are significant at the $5 \%$ level or better based on White-adjusted standard errors.
} 
The number and type of shareholders is also related to message-posting activity. A $10 \%$ increase in the number of shareholders results in about a $1 \%$ increase in the number of postings. On the other hand, a $10 \%$ increase in institutional holdings results in a $1 \%$ decrease in postings. These results are consistent with individual shareholders being the primary drivers of message postings compared to institutional investors. Large firms, heavily traded firms also appear to attract more postings. I find that a $10 \%$ increase in average monthly trading volume or a $10 \%$ increase in market value results in a $2.3 \%$ and $3.4 \%$ increase, respectively, in the number of firm message postings.

Finally, consistent with the predictions presented in section 2, I find that message-posting volume is increasing in analyst following. Each additional analyst is associated with a $2.1 \%$ increase in average posting volume. This is consistent with the anecdotal evidence that investors often discuss and debate analyst whisper numbers. Moreover, firms with greater analyst following also tend to have characteristics (i.e. large information asymmetry) which will spawn more posting activity.

\subsection{Analysis of Time-Series Data}

The determinants of daily changes in posting volume are presented in Table 3 . The table presents the mean regression coefficients from 50 firm-specific time-series regressions. Each time-series sample consists of 165 daily observations of message-posting volume and stock market activity. The regression results support the story that message-posting volume reacts to information events. For example, there are $17.3 \%, 26.8 \%$, and $77.7 \%$ more postings on the day before, the day of, and the day after a firm earnings announcement compared to other trading days in the sample. This is consistent with investors anticipating and reacting to news in eamings announcement events. In addition, it is consistent with the disagreement story and trade stories where investors will post more messages if they have different interpretations about the content of an earnings announcement event.

Contemporaneous changes in trading volume and the absolute value of abnormal returns are related to changes in posting activity. A $10 \%$ increase in trading volume results in a $3.1 \%$ 
increase in postings. A negative abnormal return will lead to a $2.8 \%$ increase in same period postings, while the size of positive gains is less dramatic. On the other hand, a $1 \%$ change in yesterday's abnormal return (either direction) leads to a $1.9 \%$ increase in posting volume. Investors seem to react more quickly to negative information.

The regression results show that changes in daily posting volume are positively autocorrelated. A $1 \%$ increase in yesterday's postings is expected to increase today's postings by $0.23 \%$. Changes in aggregate posting activity are contemporaneously correlated with firmspecific changes in postings. After controlling for firm-specific market activity, there appear to be economy-wide drivers of daily changes in posting activity. The regression coefficient on aggregate posting activity indicates that a $10 \%$ increase in aggregate postings will lead to a $1.6 \%$ increase in firm-specific postings.

In summary, daily variation in real market activity and firm-specific information events, on average, explains more than $46 \%$ of the variation in daily changes in message postings.

\section{Prediction of Stock Trading Volume}

The determinants of next-day stock trading volume are presented in Table 4. The table presents the mean regression coefficients from 50 firm-specific time-series regressions. Each time-series sample consists of 165 daily observations of daily trading volume and lagged message-posting volume and stock market activity. I examine the ability of previous day and overnight postings to predict next day trading volume. A $10 \%$ increase in yesterday's trading volume leads to a $2.5 \%$ average increase in today's trading volume. A $10 \%$ increase in overnight postings lead to a $1.5 \%$ average increase in next day volume. Therefore, the release of information after trading hours and the processing of the information by investors leads to postings and subsequent trade. Interestingly, changes in previous trading day posting volume have no predictive ability for next day trading volume. It appears that information discussed on message boards is quickly reflected in trading volume. This is consistent with anecdotal evidence that message postings react quickly to market events. 


\section{Prediction of Abnormal Variance}

Table 5 presents the stock return variance prediction results. Again, the table presents the mean regression coefficients from 50 firm-specific time-series regressions. I examine the ability of previous day and overnight postings to predict next day absolute value of abnormal returns. The results are consistent with persistence in the variance of returns. High variance yesterday tends to lead to high variance today. In particular, a $+/-10 \%$ abnormal return yesterday is expected to lead to a $+/-1.1 \%$ abnormal return today. In addition, a $100 \%$ increase in yesterday's trading volume is expected to lead to $\mathrm{a}+/-0.2 \%$ abnormal return today.

After controlling for other predictive variables, a $100 \%$ increase in overnight postings leads to an average $+/-0.3 \%$ abnormal daily return over the next trading day. It should be noted that these returns are calculated from the close of day $t-1$ to the close of day $t$. This is consistent with the idea that overnight postings reflect news (either good or bad) that will be reflected in next day prices. However, changes in previous trading day message-posting volume have no predictive ability for next day abnormal returns. Again, it appears that posting information is quickly impounded in stock prices.

It is interesting to note that the variance of returns is significantly higher the day of and the day after an earnings announcement. This is consistent with high uncertainty around earnings announcement events. The spill-over effect to the following trading day could also reflect the fact that earnings numbers are often released after trading hours. Therefore, investors could not trade on this information until the next day.

\section{Prediction of Abnormal Returns}

Table 6 presents the forecasting results for next day abnormal stock returns. I examine the ability to previous day and overnight postings to predict next day actual abnormal returns. Previous day returns, changes in trading volume, and changes in previous trading day postings have no predictive ability for stock returns. On the other hand, a $100 \%$ increase in overnight postings leads to a $0.18 \%$ average abnormal return from the close of day $t-1$ to the close of day $t$. 
Therefore, overnight postings appear predict next day returns. The question is whether this result implies a feasible trading strategy? The returns presented in this analysis are based on close-toclose price changes. An investor might not be able to profitably trade on message-board information because of the opening auction on daily trading could eliminate any information advantage. However, the results indicate that changes in overnight posting activity contain valuerelevant information. They also show that increases in overnight posting volume generally indicate positive news about stock prices. On average, increased posting volume does not lead to next-day price drops. This descriptive evidence does not appear to support the short-seller hypothesis about intra-day posting activity.

It is interesting to note that the regression indicates positive abnormal returns 1 and 2 days before the earnings announcement events. This could be a period/sample-specific phenomenon.

\section{Discussion and Conclusion}

This paper provides the first systematic evidence on the determinants of message posting activity on Internet stock message boards. The empirical tests investigate if variation in message-posting volume is related to investor reaction to and processing of information, rational incentives for investors to gather information, or irrational or behavioral market activity. I conduct the analysis using a sample of over 3,000 stocks listed on Yahoo! message boards on July 1, 1998. I find that total message-posting volume is, on average, higher for firms with extreme past stock returns and accounting performance, higher price-earnings and book-tomarket ratios, higher past volatility and trading volume, higher analyst following, and lower institutional holdings. Firms with high market capitalization and firms in the technology, service and healthcare industries also tend to have higher posting volume.

I also examine changes in daily message posting volume for 50 of the most active stocks listed on Yahoo! message boards between January and August 1998. The time-series results show that daily posting volume increases during earnings announcement periods and is associated with contemporaneous changes in daily trading volume and stock returns and with 
prior day stock returns. I also find that, after controlling for previous day stock returns and trading volume, changes in overnight posting volume predict next day trading volume and abnormal stock returns.

One interpretation of the empirical results is that posters focus on firms with the largest information asymmetry, the poorest accounting information, the highest uncertainty and risk, and the greatest likelihood of generating future information flows. Therefore, high posting activity is consistent with investors responding to rational incentives to gather, process, and react to information. On the other hand, variation in message-posting activity could have a behavioral explanation. The high posting volume for technology firms, high price-earnings and high marketto-book firms, and firms with extreme past performance could be interpreted as irrational fixation on "glamour stocks" or dated information.

There are numerous possible extensions to this study. I have currently collected data on short-sale positions for NASDAQ stocks in the sample. Future drafts of this paper will test whether short-seller activity affects posting volume. In addition, I have collected information on the electronic "alias" of individual message posters for each of the 50 firms in time-series sample. I plan to investigate whether the concentration of postings by individuals leads to differences in the association between posting volume and market activity. 


\section{References}

Bagnoli, M., M. Beneish, and S. Watts, 1998, Whispers and shouts: Forecasts of quarterly earnings per share, Working paper, University of Michigan, 1998.

Batsell, J., 1998, Gossip central - Internet message boards can leave some stocks hanging by a thread, The Seattle Times, September 14, 1998.

Bennett, J., 1998, Traffic on financial web pages rises when the market falls, Dow Jones News Service, September 1, 1998.

Bhushan, R., 1989, Firm characteristics and analyst following, Journal of Accounting and Economics 11, 255-274.

De Bondt, W., and R. Thaler, 1985, Does the stock market overreact?, Journal of Finance 40, 793-805.

De Long, J., A. Shleifer, L. Summers, and R. Waldman, 1990, Noise trader risk and financial markets, Journal of Political Economy 98, 703-738.

Diamond, D., 1985, Optimal release of information by firms, Journal of Finance 40, 1071-1094.

French, K. and R. Roll, 1986, Stock return variances: The arrival of information and the reaction of traders, Journal of Financial Economics 17, 5-26.

Goldstein, A., 1998, Money messages: Electronic message boards are a good way to get investing facts and fiction, The Dallas Morning News, August 3, 1998, 1 D.

Harmon, A., 1998, The market turmoil: Investors on line, The New York Times, September 1, 1998, 6 .

Harris, M. and A. Raviv, 1993, Differences of opinion make a horse race, Review of Financial Studies 6, 473-506.

Kandel, E. and N. Pearson, 1995, Differential interpretation of public signals and trade in speculative markets, Journal of Political Economy 103, 831-872.

Kim, O. and R. Verrecchia, Market reaction to anticipated announcements, Journal of Financial Economics 30, 273-309.

Lakonishok, J., A. Shleifer, and R. Vishny, 1994, Contrarian Investment, Extrapolation, and Risk, Journal of Finance 49, 1541-1578.

Landwehr, R., 1998, Companies battle libel on the Web, Denver Business Journal, October 19, 1998, A3. 
Lee, C., A. Shleifer, and R. Thaler, 1991, Investor sentiment and the closed-end fund puzzle, Journal of Finance 46, 75-109.

Maremount, M., 1998, Predeal trading in U.S. Surgical puts spotlight on cyberinvestors, The Wall Street Journal, May 28, 1998, Cl.

Medill, G., 1998, Chicago firm wants to know what Yahoo! left messages, Chicago Daily Herald, October 12, 1998, 4. 


\section{Table 1}

\section{Descriptive Statistics for Cross-sectional Sample}

Sample consists of 3,478 firms with (a) Yahoo! message boards on July 1, 1998, (b) accounting and stock price information on 1997 Compustat database, (c) monthly return and volume data on 1997 CRSP database, and (d) analyst following, shareholder, and institutional holding data from 1997 Disclosure database. Firms missing the aforementioned information are removed from the sample. Firms $\mathrm{PE}$ and $\mathrm{MB}$ ratios more than 4 standard deviations from their respective sample means were removed from the sample.

Panel A- Categories of Firms

\begin{tabular}{lcc}
\hline & $\begin{array}{c}\text { Number of } \\
\text { Firms }\end{array}$ & $\begin{array}{c}\text { Mean Number of } \\
\text { Postings }\end{array}$ \\
\hline All Firms & $3478(100 \%)$ & 272 \\
Basic Materials & $275(7.9 \%)$ & 126 \\
Capital Goods & $244(7.0 \%)$ & 88 \\
Conglomerates & $24(0.7 \%)$ & 198 \\
Consumer Cyclical & $246(7.1 \%)$ & 169 \\
Consumer NonCyclical & $149(4.3 \%)$ & 147 \\
Energy & $145(4.2 \%)$ & 250 \\
Financial & $608(17.5 \%)$ & 63 \\
Healthcare & $363(10.4 \%)$ & 403 \\
Services & $581(16.7 \%)$ & 247 \\
Technology & $645(18.5 \%)$ & 670 \\
Transportation & $78(2.2 \%)$ & 245 \\
Utilities & $120(3.5 \%)$ & 43 \\
& & \\
NYSE & $1146(32.9 \%)$ & 258 \\
DIVIDEND & $1405(40.4 \%)$ & 162 \\
\hline
\end{tabular}

Panel B - Sample Statistics

\begin{tabular}{lccc}
\hline & Mean & Median & Std. Dev. \\
\hline ROE & -0.032 & 0.101 & 3.01 \\
$\triangle$ ROE & -0.042 & 0.020 & 2.46 \\
RETURN & 0.243 & 0.227 & 0.549 \\
VOL & 0.127 & 0.108 & 0.075 \\
PE & 13.34 & 15.95 & 35.47 \\
MB & 3.36 & 2.27 & 5.78 \\
BETA & 0.97 & 0.88 & 0.61 \\
ANALYST & 3.53 & 1 & 5.80 \\
MVE & 1974 & 173 & 9302 \\
VOLUME & 36738 & 10671 & 75447 \\
INSTIT & $35.34 \%$ & $32.12 \%$ & $26.51 \%$ \\
NUMSHR & 11904 & 927 & 153377 \\
\hline
\end{tabular}




\section{Table 1 - continued \\ Definition of Cross-sectional Variables}

\section{Variable Name}

\section{NYSE}

ROE

Low ROE

High ROE

$\triangle \mathrm{ROE}$

Low $\triangle R O E$

High $\triangle R O E$

Low RETURN

High RETURN

PE

MB

DIVIDEND

VOLATILTY

BETA

\# Shareholders

$\%$ Institutions Holdings

Trading Volume

Mkt Value Equity

\# Analysts

\section{$\underline{\text { Description }}$}

Dummy variable equal to 1 if firm trades on the NYSE, 0 otherwise.

Earnings before extra. items divided by book value of common equity in 1997.

Dummy variable equal to 1 if firm is in lowest ROE quartile, 0 otherwise.

Dummy variable equal to 1 if firm is in highest ROE quartile, 0 otherwise.

Change in ROE from 1996 to 1997.

Dummy variable equal to 1 if firm is in lowest $\triangle R O E$ quartile, 0 otherwise.

Dummy variable equal to $\mathrm{I}$ if firm is in highest $\triangle R O E$ quartile, 0 otherwise.

Dummy variable equal to $l$ if firm is in lowest RETURN quartile and zero otherwise.

Dummy variable equal to 1 if firm is in highest RETURN quartile, 0 otherwise.

Price-to-earnings multiple at the end of fiscal year 1997.

Market-to-book ratio at the end of fiscal year 1997.

Dummy variable equal to 1 if firm paid dividend in 1997, 0 otherwise.

Standard deviation of firm monthly stock returns (Jan,1996-Dec.1997).

Monthly market beta based on monthly returns (Jan.1996-Dec.1997).

Number of firm shareholders at end of fiscal 1997.

$\%$ of outstanding shares held by institutions in 1997.

Average number of shares traded per month during 1997.

Market value of common equity (\$) at end of 1997.

Number of analysts following stock as reported by IBES during 1997.

\section{Industry Classifications}

Constant (Basic Materials)

Capital Goods

Conglomerates

Consumer Cyclical

Consumer Noncyclical

Energy

Finance

Healthcare

Services

Technology

Transportation

Utilities 
Table 2

\section{Cross-sectional determinants of stock message postings}

Regression of natural logarithm of total messages posted on July 1, 1998 on firm characteristics. Cross-sectional sample consists of 3,478 firm observations. Variable definitions are listed in Table 1.

Dependent Variable $=\ln ($ Messages $)$

Coefficient White std error White t-statistic

Constant (Basic Materials)

Capital Goods

Conglomerates

Consumer Cyclical

Consumer Noncyclical

Energy

Finance

Healthcare

Services

Technology

Transportation

Utilities

NYSE

LOW ROE

HIGH ROE

LOW $\triangle$ ROE

HIGH $\triangle$ ROE

LOW RETURN

HIGH RETURN

PE

MB

DIVIDEND

VOLATILTY

BETA

LOG(\# Shareholders)

$\%$ Institutions Holdings

LOG(Trading Volume)

LOG(Mkt Value Equity)

\# Analysts

Adjusted $\mathrm{R}^{2}$

\section{$-2.922$}

0.093

$-0.002$

0.177

0.329

0.062

$-0.542$

0.577

0.266

0.840

0.069

$-0.441$

$-0.134$

0.474

0.111

0.094

0.483

0.281

0.223

0.001

0.010

$-0.662$

2.756

$-0.003$

0.103

$-0.010$

0.234

0.339

0.021

$45.0 \%$
0.280

0.117

0.257

0.114

0.133

0.144

0.100

0.111

0.101

0.101

0.168

0.121

0.067

0.085

0.060

0.071

0.062

0.066

0.060

0.00038

0.005

0.064

0.421

0.045

0.018

0.001

0.019

0.026

0.005

13.17

3.95
$-10.42$

0.80

$-0.01$

1.55

2.48

0.43

$-5.44$

5.19

2.65

8.28

0.41

$-3.65$

$-2.00$

5.57

1.86

1.32

7.80

4.25

3.71

3.53

2.00

$-10.37$

6.55

$-0.07$

5.78

$-8.68$

12.51 
Table 3

\section{Time-series determinants of daily message postings}

Sample consists of 165 daily observations of Yahoo! message-posting volume and stock market activity from January 2, 1998 to August 26, 1998 for 50 firms. The 50 firms were chosen based on the highest cumulative message posting activity on Yahoo! message boards on July I, 1998. The table presents the mean regression results from 50 firm-specific time-series regressions.

Dependent variable: $\quad$ Postings $(\mathrm{t}) /$ Avg(Postings Prior 5 days $)$

\begin{tabular}{|c|c|c|c|c|}
\hline & & $\begin{array}{c}\text { Mean } \\
\text { Coefficient }\end{array}$ & $\begin{array}{l}\text { Std error } \\
\text { of Mean }\end{array}$ & t-statistic \\
\hline \multicolumn{2}{|l|}{ Constant } & 0.323 & 0.049 & 6.55 \\
\hline \multicolumn{2}{|l|}{ Time } & -0.0008 & 0.0002 & -3.92 \\
\hline \multicolumn{2}{|l|}{ Monday } & -0.303 & 0.021 & -14.25 \\
\hline \multicolumn{2}{|l|}{ Tuesday } & -0.049 & 0.024 & -2.06 \\
\hline \multicolumn{2}{|l|}{ Wednesday } & -0.042 & 0.019 & -2.21 \\
\hline \multicolumn{2}{|c|}{ Thursday } & 0.013 & 0.030 & 0.44 \\
\hline \multicolumn{2}{|c|}{ Earnings Announcement (-2) } & 0.091 & 0.053 & 1.72 \\
\hline \multicolumn{2}{|c|}{ Earnings Announcement (-1) } & 0.173 & 0.057 & 3.05 \\
\hline \multicolumn{2}{|c|}{ Earnings Announcement (0) } & 0.268 & 0.127 & 2.11 \\
\hline \multicolumn{2}{|c|}{ Earnings Announcement (1) } & 0.777 & 0.177 & 4.38 \\
\hline \multicolumn{2}{|c|}{ Earnings Announcement (2) } & -0.432 & 0.067 & -6.41 \\
\hline \multicolumn{2}{|c|}{ Postings(t-1)/Avg(PostingSPrior 5 days $)$} & 0.233 & 0.018 & 13.19 \\
\hline \multicolumn{2}{|c|}{ AggPostings $(t) /$} & \multicolumn{2}{|c|}{ Avg(AggPostings) } & 4.33 \\
\hline \multicolumn{2}{|c|}{ Volume $(\mathrm{t}) / \operatorname{Avg}\left(\right.$ Volume $\left._{\text {Prior } 5 \text { days }}\right)$} & 0.312 & 0.035 & 8.93 \\
\hline \multicolumn{2}{|c|}{ Volume(t-1)/Avg(Volume Prior 5 days $)$} & 0.024 & 0.032 & 0.74 \\
\hline \multicolumn{2}{|c|}{$\mid$ Abnormal Return(t)| } & 2.758 & 1.157 & 2.38 \\
\hline \multicolumn{2}{|c|}{$\mid$ Abnormal Return $\left.(\mathrm{t})\right|^{*}$ Positive $(\mathrm{t})$} & -1.805 & 0.897 & -2.01 \\
\hline \multicolumn{2}{|c|}{ Abnormal Return(t-1)| } & 1.889 & 0.599 & 3.15 \\
\hline \multicolumn{2}{|c|}{$\mid$ Abnormal Return $\left.(\mathrm{t})\right|^{*}$ Positive $(\mathrm{t}-1)$} & -0.101 & 0.719 & -0.14 \\
\hline \multicolumn{2}{|l|}{ Adjusted $\mathrm{R}^{2}$} & $46.6 \%$ & & \\
\hline \multicolumn{5}{|c|}{ (s) } \\
\hline Monday & \multicolumn{4}{|c|}{ Dummy variable equal to $l$ if trading day is Monday, 0 otherwise. } \\
\hline Tuesday & \multicolumn{4}{|c|}{$\begin{array}{l}\text { Dummy variable equal to } l \text { if trading day is Monday, } 0 \text { otherwise. } \\
\text { Dummy variable equal to } l \text { if trading day is Tuesday, } 0 \text { otherwise. }\end{array}$} \\
\hline Wednesday & \multicolumn{4}{|c|}{ Dummy variable equal to 1 if trading day is Wednesday, 0 otherwise. } \\
\hline Thursday & \\
\hline $\begin{array}{l}\text { Earnings Announcement(z) } \\
\text { Volume(t) }\end{array}$ & $\begin{array}{l}\text { Dummy variable equal to } l \text { if day } t \text { is } z \text { days after an earnings announcement. } \\
\text { \# shares traded on day } t \text {. }\end{array}$ & \multicolumn{3}{|c|}{$\begin{array}{l}\text { Dummy variable equal to } l \text { if trading day is Thursday, } 0 \text { otherwise. } \\
\text { Dummy variable equal to } l \text { if day } t \text { is } z \text { days after an earnings announcement. }\end{array}$} \\
\hline $\mid$ Abnormal Return $(t) \mid$ & \multicolumn{4}{|c|}{$\begin{array}{l}\text { The absolute value of day } t \text { abnormal stock return. Abnormal return calculated } \\
\text { as firm stock return (close day } t-1 \text { to close day } t \text { ) minus daily NYSE Composite } \\
\text { return (close day } t-1 \text { to close day } t \text { ). }\end{array}$} \\
\hline Positive(t) & \multicolumn{4}{|c|}{$\begin{array}{l}\text { return (close day } t-1 \text { to close day } t \text { ). } \\
\text { Dummy variable equal to } 1 \text { if } A \text { bnormal Return }(t) \geq 0,0 \text { otherwise. }\end{array}$} \\
\hline
\end{tabular}




\section{Table 4}

\section{Time-series determinants of daily trading volume}

Sample consists of 165 daily observations of Yahoo! message-posting volume and stock market activity from January 2, 1998 to August 26, 1998 for 50 firms. The 50 firms were chosen based on the highest cumulative message posting activity on Yahoo! message boards on July 1, 1998. The table presents the mean regression results from 50 firm-specific time-series regressions.

Dependent variable: $\quad$ Volume(t)/Avg(Volume Prior $s$ days $\left._{\text {S }}\right)$

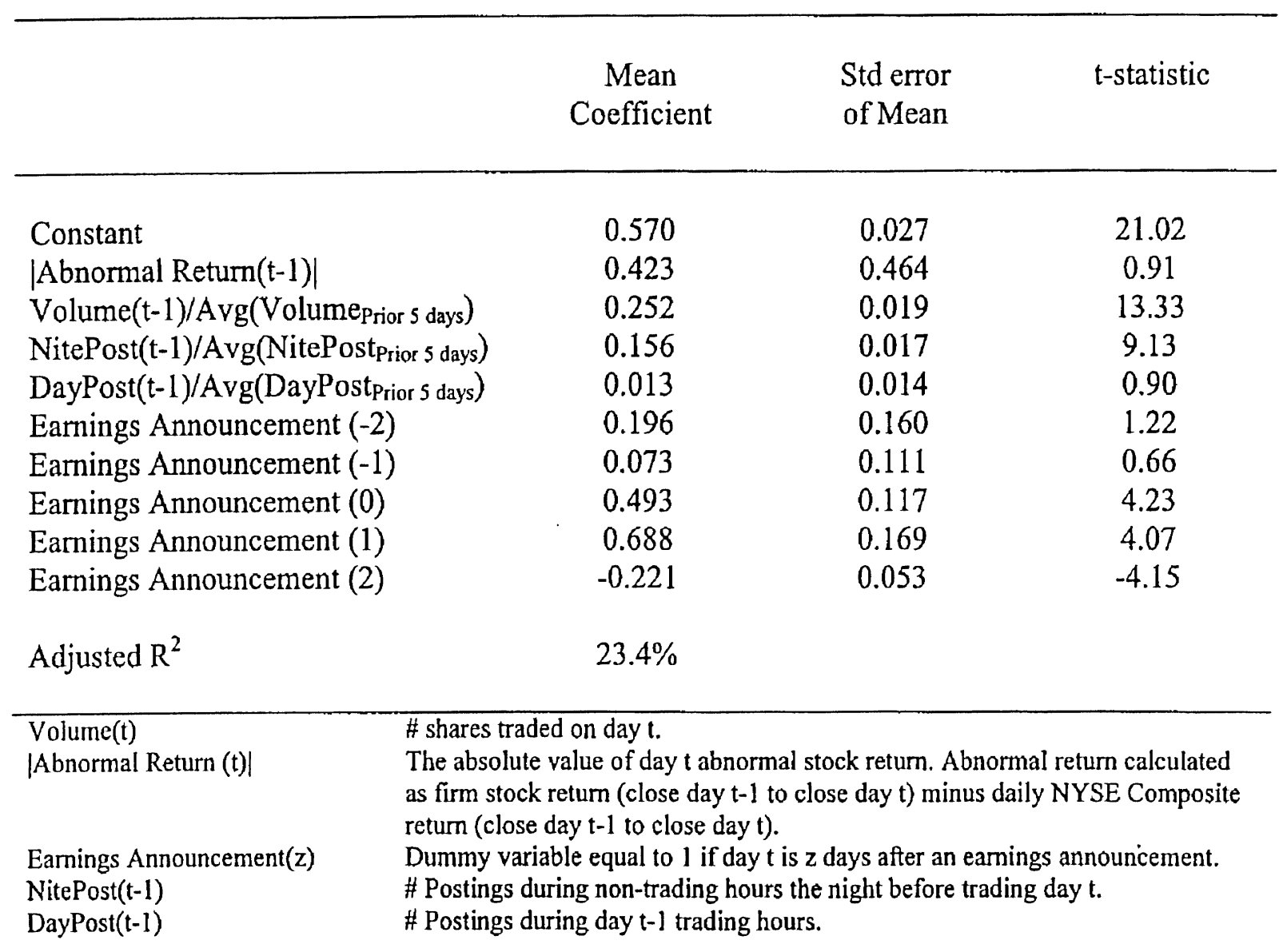




\section{Table 5}

\section{Time-series determinants of daily abnormal return variance}

Sample consists of 165 daily observations of Yahoo! message-posting volume and stock market activity from January 2, 1998 to August 26, 1998 for 50 firms. The 50 firms were chosen based on the highest cumulative message posting activity on Yahoo! message boards on July 1, 1998. The table presents the mean regression results from 50 firm-specific time-series regressions.

Dependent variable: $\quad$ |Abnormal Return(t)|

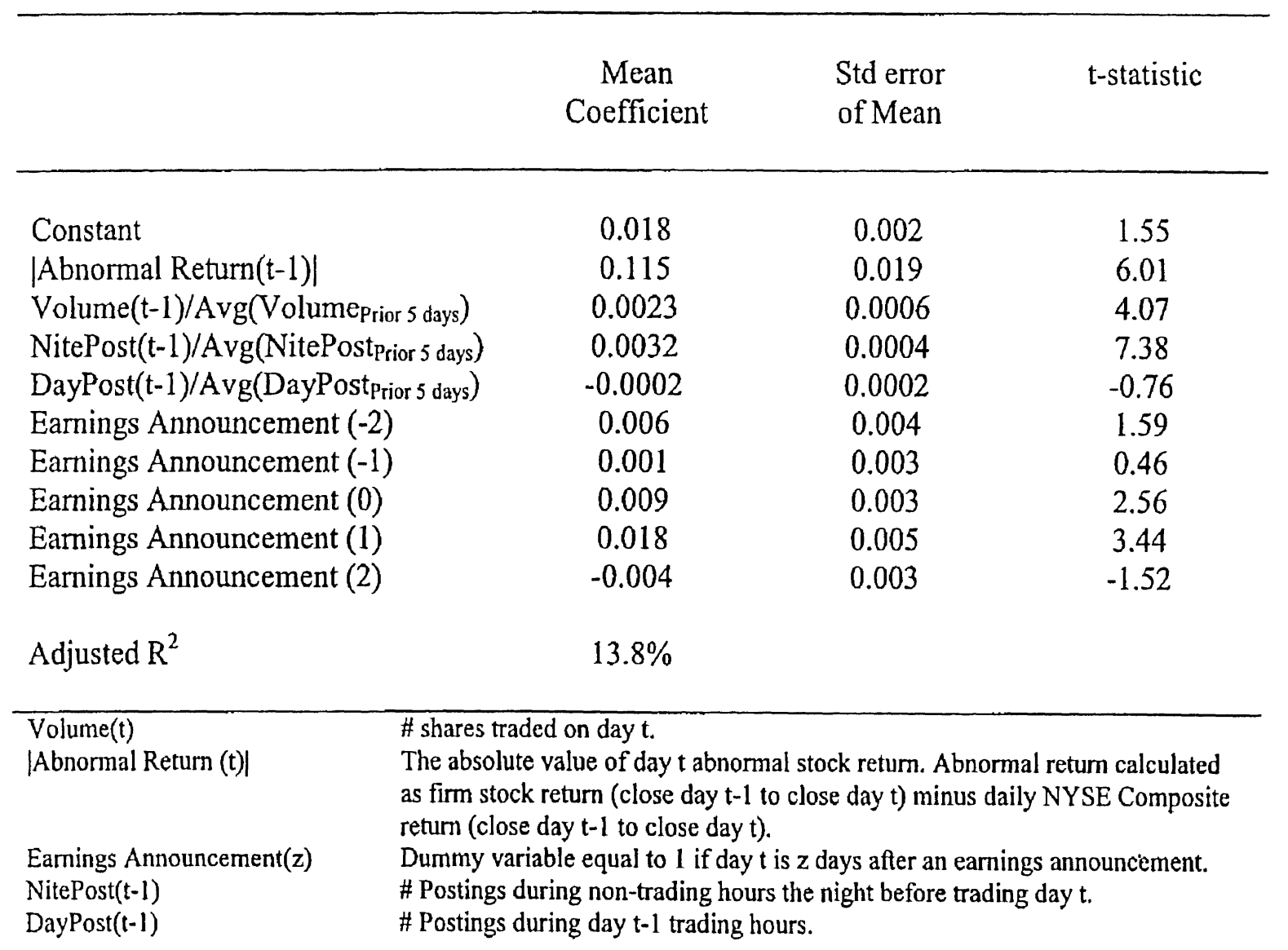


Table 6

Time-series determinants of daily abnormal return

Sample consists of 165 daily observations of Yahoo! message-posting volume and stock market activity from January 2, 1998 to August 26, 1998 for 50 firms. The 50 firms were chosen based on the highest cumulative message posting activity on Yahoo! message boards on July I, 1998. The table presents the mean regression results from 50 firm-specific time-series regressions.

Dependent variable: Abnormal Return( $(t)$

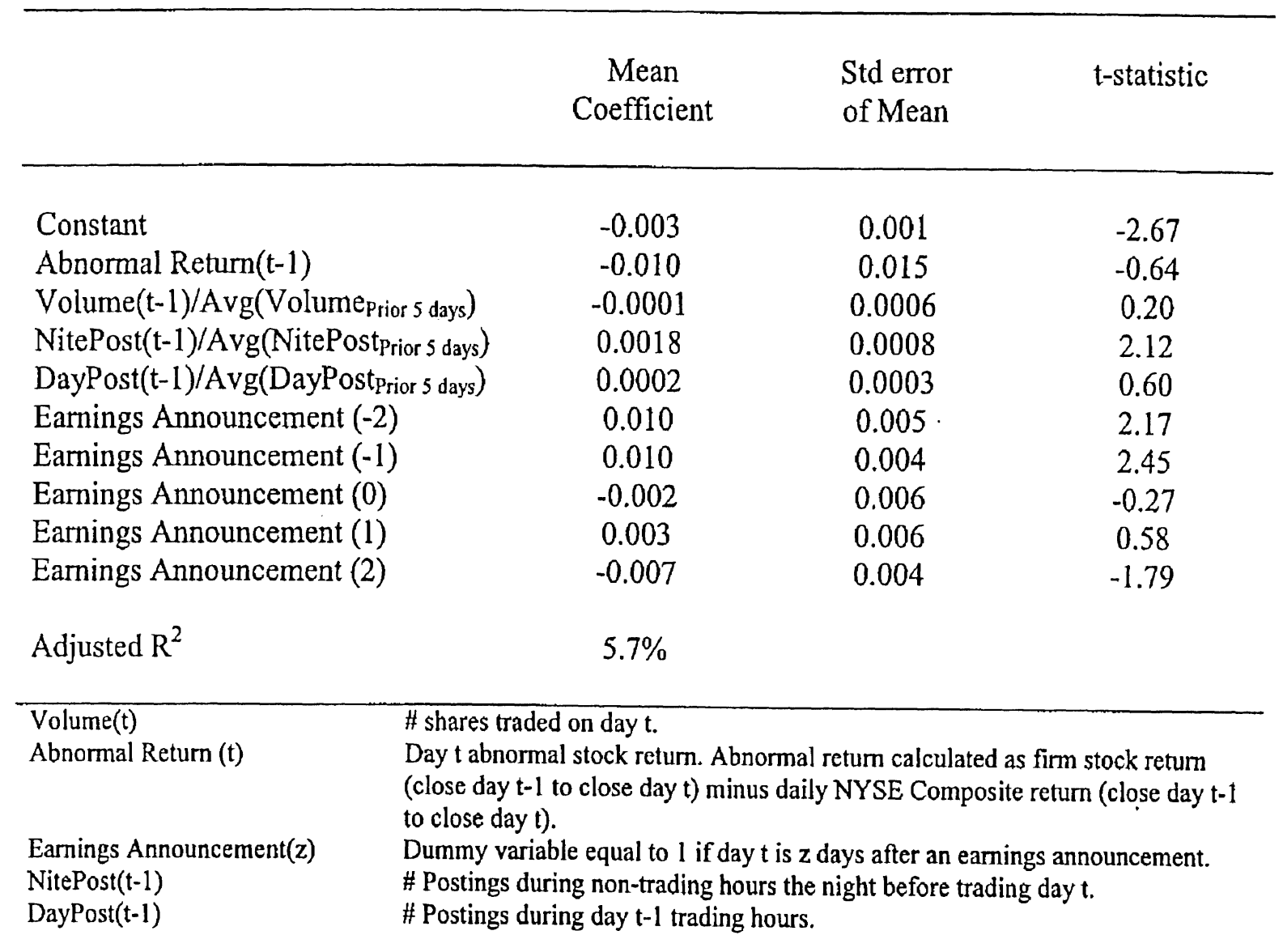


Figure 1:

Daily Message-Posting Volume for Top 100 Yahoo! Stocks

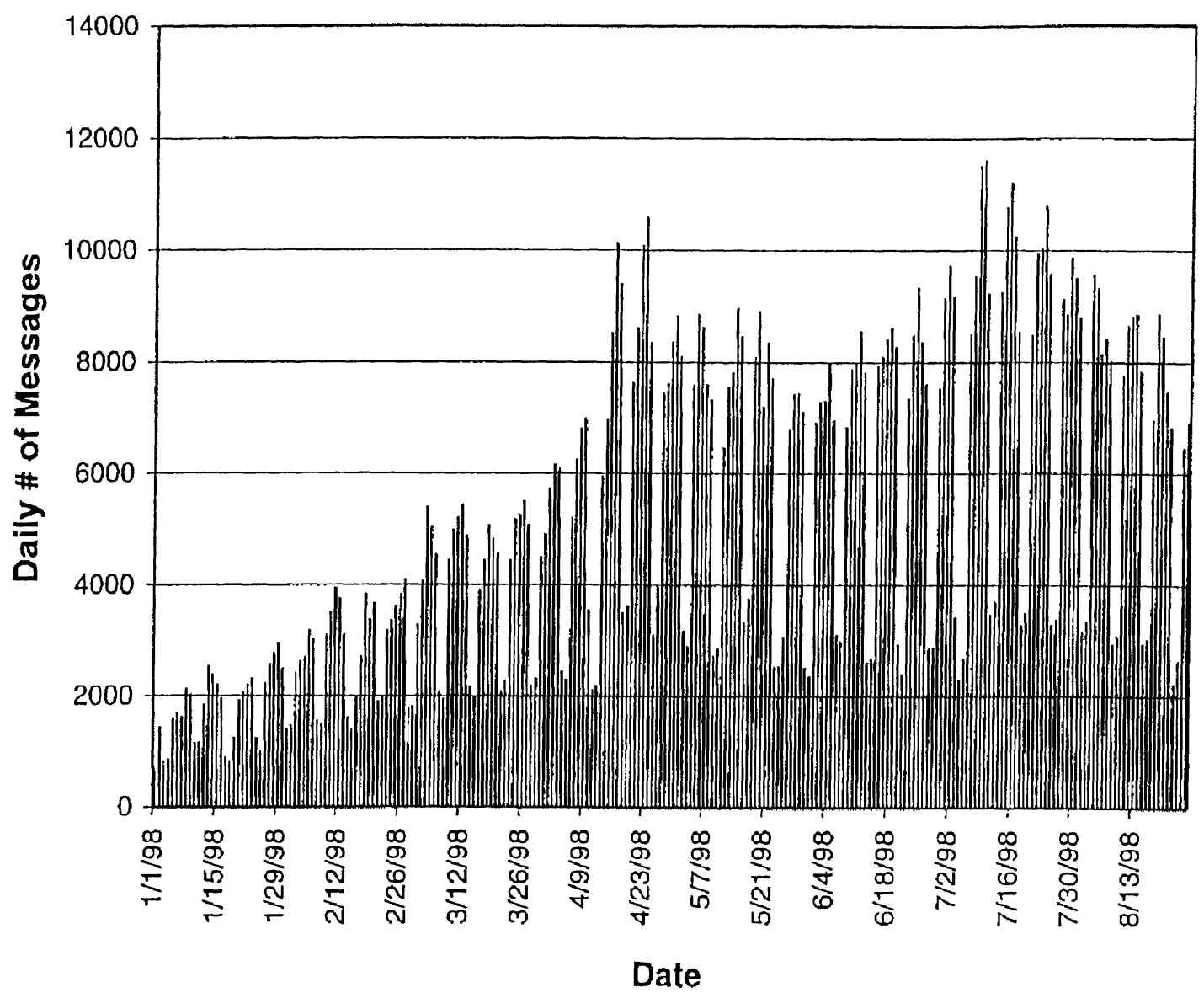


Figure 2:

Intraday Message Postings: Top 100 Yahoo Stocks

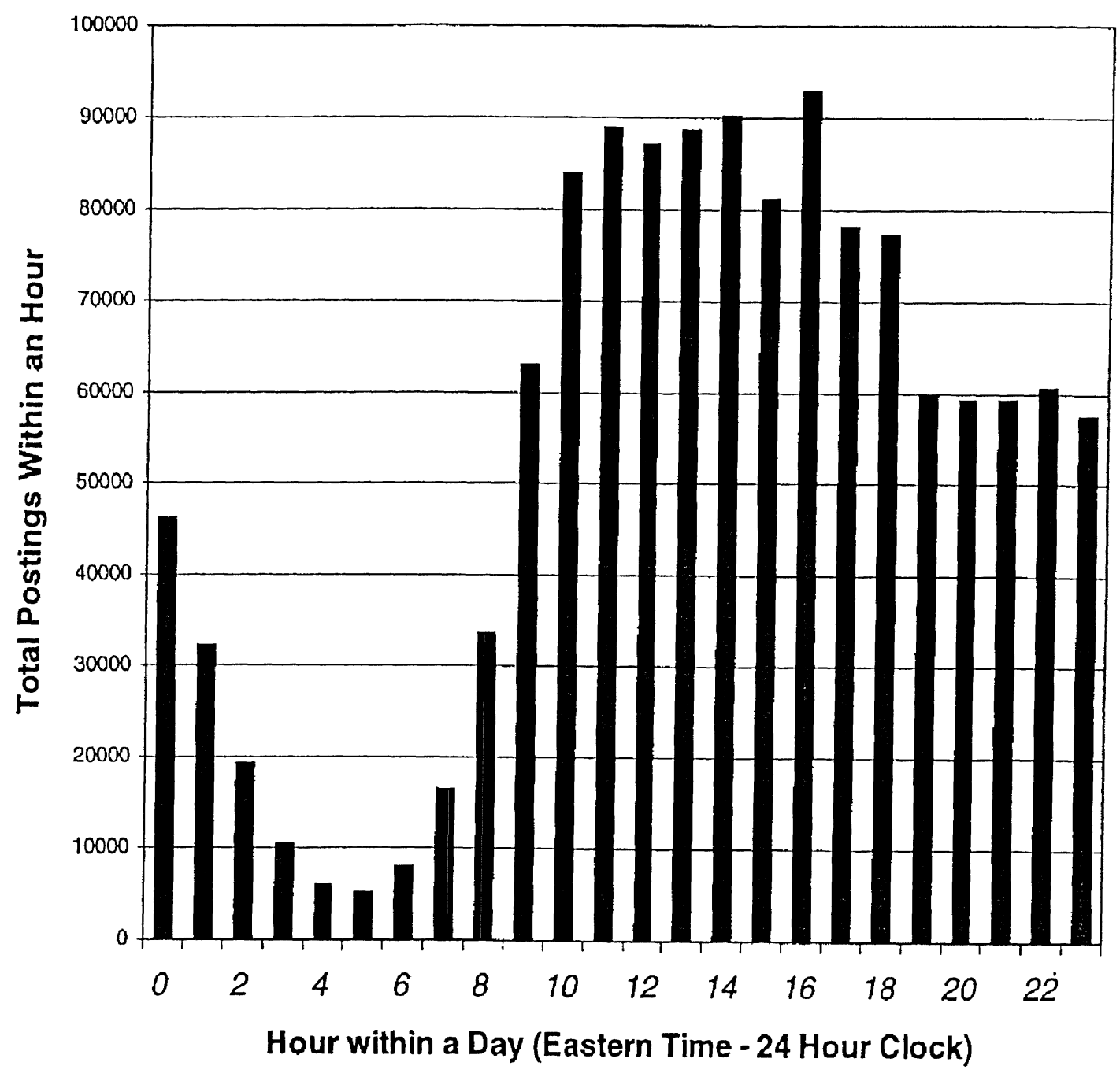


Figure 3:

Distribution of Message Postings

$(8,011$ Yahoo Stocks, July 1, 1998)

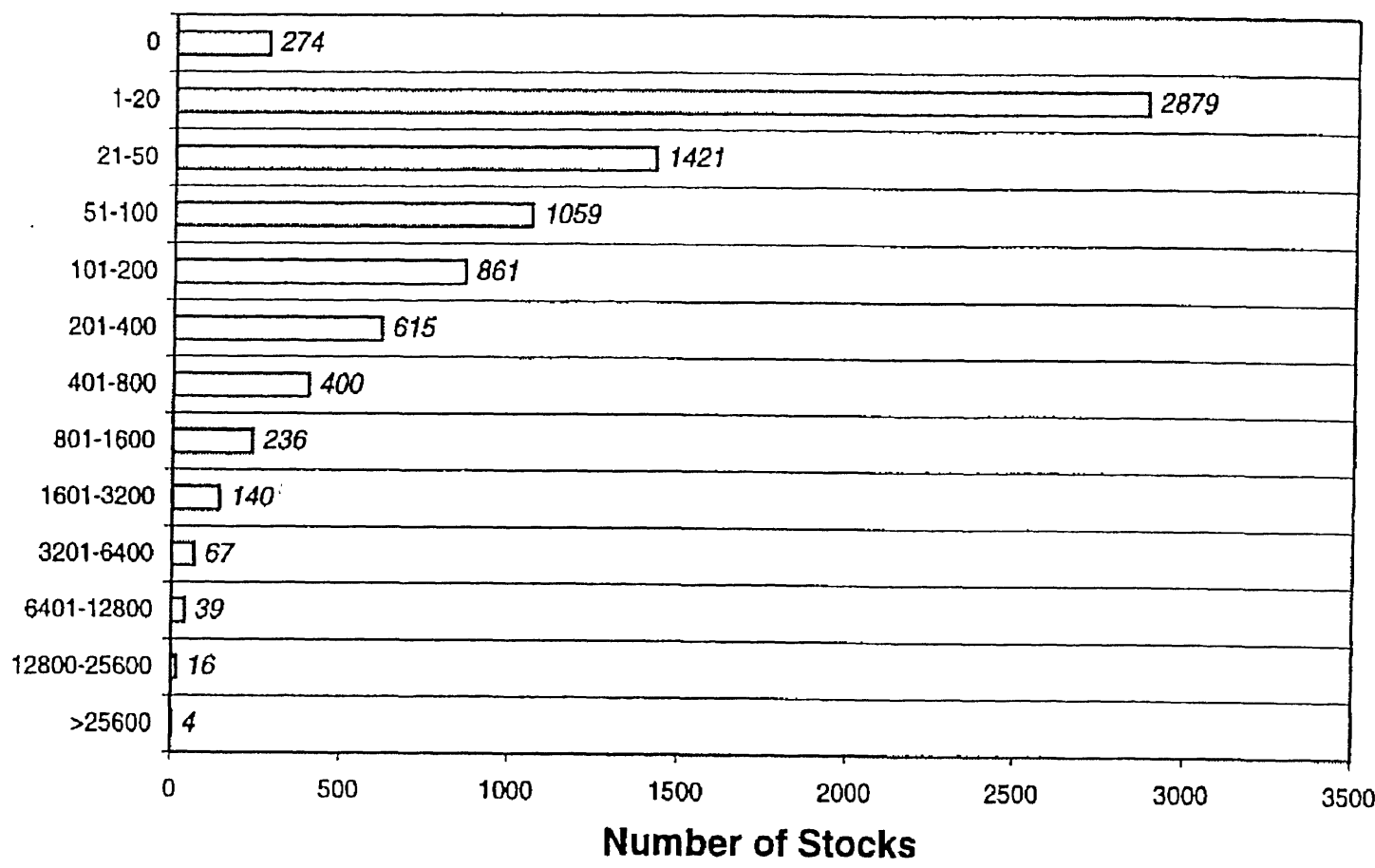

Interpretation Example:

"As of July 1, 1998, there were 615 stocks which had between 201 and 400 cumulative messages posted on Yahool message boards. Total message count is based on message postings between December 97 and June $98 . "$ 